\title{
Analisis Current Ratio, Debt To Equity Ratio, Total Assets Turn Over dan Net Profit Margin dalam Menilai Kinerja Keuangan Perusahaan Sektor Aneka Industri pada Bursa Efek Indonesia 2016-2019
}

\author{
Rosalinda Tania ${ }^{1}$, Benny Rojeston Marnaek Nainggolan ${ }^{2}$ \\ ${ }^{1,2)}$ Universitas Prima Indonesia, Indonesia \\ rosalindatania11@gmail.com, benny.bppk@gmail.com
}

$\begin{array}{ll}\text { *Penulis Korespondensi } \\ \text { Diajukan } & : 04 \text { Mei } 2021 \\ \text { Disetujui } & : \text { 20 Mei } 2021 \\ \text { Dipublikasi } & : 2 \text { Agustus 2021 }\end{array}$

\begin{abstract}
This study aims to analyze and know the influence of Current Ratio, Debt To Equity Ratio, Total Assets Turn Over and Net Profit Margin in assessing the Financial Performance of Multi-Industry Sector Companies in the period 2016-2019. Independent variables used are Current Ratio, Debt To Equity Ratio, Total Assets Turn Over and Net Profit Margin while dependent variable in this study is Financial Performance represented by Return On Asset. The method used is quantitative method, The type of research is correlation between connecting independent and dependent variable. Research described causal relationship. The sampling technique used is purposive sampling. Sample is defined as part of the population with certain criteria and amount. Samples used in the study of 13 companies. The tests used are classic assumption tests, multiple linear analysis research models, and the coefficients of determination are simultaneous and partial tests. The results showed that partial current ratio and debt to equity ratio have no effect on financial performance while Total Assets Turn Over and Net Profit Margin affect financial performance. Adjusted $R$ Square test results explain 97.4\% of dependent variables can be explained by independent variables while the remaining $2.6 \%$ is not explained. The conclusion from the results of this test that two variables namely Current ratio and Debt To Equity Ratio which does not affect Financial Performance.
\end{abstract}

Keywords: Finance. Method. Profit. Purposive. Quantitative.

\section{PENDAHULUAN}

Perusahaan sektor aneka industri meliputi industri otomotif, textile dan garmen, kabel, alas kaki dan elektronika. Perusahaan sektor aneka industri adalah kumpulan dari berbagai perusahaan industri manufaktur yang memiliki tingkat permintaan yang fluktuatif. Perusahaan sektor ini rawan hancur jika terjadi krisis karena dapat melemahkan permintaan akan produk dari industri yang mengakibatkan kerugian bagi perusahaan. Namun jika ekonomi melonjak maka permintaan akan mengalami kenaikan yang pesat.

Keuangan adalah masalah utama bagi perusahaan dalam menciptakan perkembangan atau perubahan pada sekitar. Perusahaan yang mempunyai kinerja yang efektif adalah perusahaan yang mampu bertahan dan menghasilkan kinerja keuangan yang baik. Begitu pula sebaliknya, perusahaan yang tidak dapat menghadapi persaingan berimbas pada buruknya kinerja keuangan atau bahkan mengalami kebangkrutan. Laporan keuangan disusun agar dapat mengetahui apakah kinerja keuangan mengalami peningkatan atau penurunan sehingga dapat mempertimbangkan keputusan di masa depan. Laporan keuangan juga dapat memperlihatkan kekuatan dan kelemahan perusahaan. Kelemahan diketahui agar manajemen dapat memperbaiki kelemahan. Kekuatan diketahui agar manajemen dapat meningkatkan dan dapat menjadi modal untuk pengambilan keputusan yang lebih baik. Dalam menganalisis laporan keuangan dibutuhkan metode dan teknik 
analisis yang tepat.

Adapun fenomena beberapa Perusahaan Sektor Aneka Industri. Fenomena terjadi pada PT. Garuda Metalindo Tbk periode 2016-2019 adalah TATO mengalami kenaikan 91.41\% namun kinerja keuangan mengalami penurunan $227.6 \%$ dan periode 2018-2019 CR mengalami kenaikan $89.09 \%$ namun kinerja keuangan mengalami penurunan $141.87 \%$ serta DER mengalami penurunan $117.3 \%$.

Fenomena yang terjadi pada PT. Trisula International Tbk adalah pada periode 2016-2017 CR mengalami kenaikan $85.39 \%$ dan TATO mengalami kenaikan $99.29 \%$ namun kinerja keuangan mengalami penurunan $151.27 \%$.

Fenomena yang terjadi pada PT. Sky Energy Indonesia Tbk periode 2017-2018 adalah CR mengalami kenaikan $86.91 \%$ tetapi kinerja keuangan mengalami penurunan $12.57 \%$ dan periode 2018-2019 DER mengalami penurunan $110.88 \%$ namun kinerja keuangan mengalami kenaikan 155.32\%. Pada periode 2017-2018 TATO mengalami kenaikan $128.78 \%$ dan NPM mengalami kenaikan $74.68 \%$ namun kinerja keuangan mengalami penurunan $125.7 \%$.

Penelitian ini merupakan kelanjutan dari penelitian _(Laela \& Hendratno, 2019) yang menemukan CR dan DER tidak berpengaruh signifikan terhadap ROA, sedangkan TATO berpengaruh signifikan terhadap ROA. Hasil lainnya oleh_(Harsi, Munandar, Yamin, \& Sus, 2017) menunjukkan CR dan TATO berpengaruh positif signifikan terhadap ROA. Penelitian ini menambahkan faktor lain yaitu NPM.

Adapun penelitian ini dilakukan dikarenakan pentingnya mengetahui kinerja keuangan agar dapat mengevaluasi efektivitas dan efisiensi perusahaan melatarbelakangi peneliti menganalisis faktor yang mempengaruhi kinerja keuangan pada sektor aneka industri ditemukan dari 45 perusahaan yang terdaftar di BEI terdapat 11 perusahaan yang mengalami kerugian. Hal ini disebabkan ketatnya persaingan dalam bidang ini maka perusahaan perlu meningkatkan kualitas dan kuantitas agar dapat bersaing pada perekonomian.

\section{Kinerja Keuangan}

\section{STUDI LITERATUR}

Mengacu_(Fahmi, 2012) Kinerja keuangan ialah kajian untuk melihat evaluasi, prediksi, dan valuasi perusahaan apakah telah menggunakan aturan-aturan keuangan. Kinerja keuangan berkaitan dengan pendapatan, operasional, struktur hutang dan investasi _(Rhamadana \& Triyonowati, 2016). Analisis informasi keuangan dapat digunakan sebagai nilai intrinsik saham dan harga saham perusahaan _(Setiyono \& Amanah, 2016). Kinerja keuangan perusahaan sangat ditentukan oleh kualitas kebijakan manajemen yang diambil dalam upaya mencapai tujuan organisasi, sehingga untuk mengukur peneliti menggunakan ROA sebagai variabel moderating untuk menilai kinerja keuangan perusahaan. Rumus ROA adalah :

$$
R O A=\frac{\text { lababersihsetelahpajak }}{\text { totalaset }}
$$

\section{Current Ratio (CR)}

Menurut (Kasmir, 2018) CR merupakan rasio likuiditas adalah salah satu indikator untuk mengukur tingkat melunasi hutang jangka pendek. Nilai CR yang rendah mengartikan bahwa perusahaan tidak mampu melunasi hutangnya. Namun jika nilai CR terlalu tinggi juga bisa diartikan sebagai aktiva perusahaan yang tidak digunakan dengan maksimal _(Wahyudi \& Sitohang, 2017). CR memberikan infornasi tentang kemampuan aktiva lancar dalam menutup hutang lancar_(Harsi, Munandar, Yamin, \& Sus, 2017). Rumus CR adalah:

\section{Debt To Equity Ratio (DER)}

$$
C R=\frac{\text { aktivalancar }}{\text { kewajibanlancar }}
$$

DER yang merupakan rasio solvabilitas adalah salah satu indikator guna menggambarkan besarnya dana dimana penyedianya yakni pemilik perusahaan dan kreditur _(Kasmir, 2018). 
Apabila DER mengalami kenaikan mengakibatkan hutang semakin tinggi dan dapat dikurangi pada perhitungan pajak sehingga DER yang tinggi meningkatkan kinerja keuangan _(Angelina, Sharon, Lim, Lombogia, \& Aruan, 2020). DER bisa digunakan untuk menganalisis laporan keuangan untuk memperlihatkan jaminan yang tersedia untuk kreditur_(Laela \& Hendratno, 2019). Rumus DER adalah:

$$
D E R=\frac{\text { totaldebt }}{\text { totalequity }}
$$

\section{Total Assets Turn Over (TATO)}

TATO yang merupakan rasio aktivitas adalah salah satu indikator untuk mengetahui tingkat efisiensi penggunaan aset _(Kasmir, 2018). Semakin besar TATO, semakin cepat laba yang dihasilkan _(Angelina, Sharon, Lim, Lombogia, \& Aruan, 2020)_semakin rendah TATO, semakin lambat perputaran aktiva untuk mendapatkan laba. Rumus TATO adalah:

$$
\text { TATO }=\frac{\text { penjualan }}{\text { totalaktiva }}
$$

\section{Net Profit Margin (NPM)}

Menurut_(Kasmir, 2018) NPM yang merupakan rasio profitabilitas adalah salah satu indikator penjualan terkait pengukuran margin laba. Besarnya NPM akan menyebabkan kinerja keuangan yang semakin membaik _(Anggraeni \& Elisa, 2020). NPM membandingkan antara laba setelah bunga dan pajak dengan penjualan _(Winarno, 2019). Rumus NPM adalah:

$$
N P M=\frac{\text { lababersih }}{\text { penjualan }}
$$

Dalam uraian diatas, maka kerangka konseptual dapat digambarkan seperti dibawah ini:

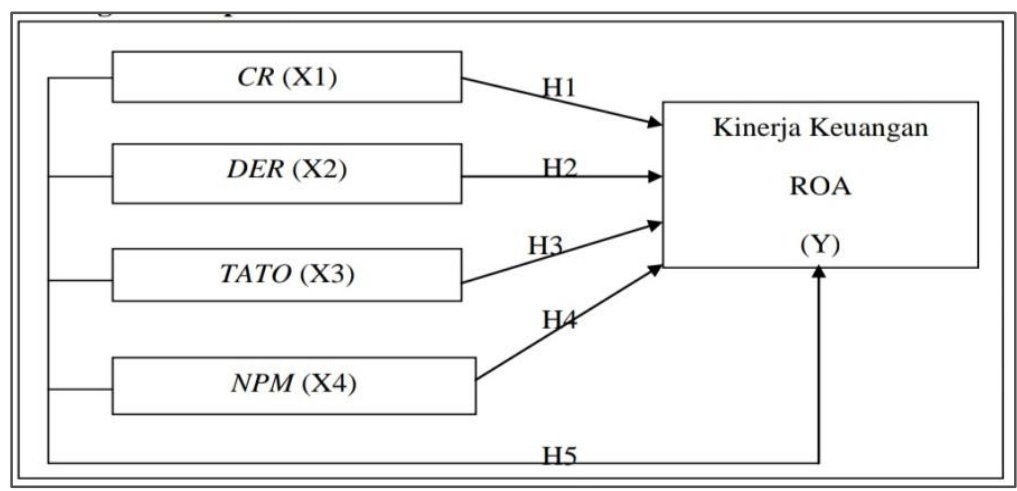

Gambar 1. Kerangka Konseptual

\section{METODE}

Menurut_(Sugiyono, 2014) Metode kuantitatif digunakan untuk menguji populasi dan sampel dengan mengumpulkan data. Dimana jenis penelitiannya yakni penelitian korelasi. Mengacu (Sugiyono, 2014) penelitian korelasi yakni cara mengkaji dengan menghubungkan variabel bebas dan terikat. Penelitian bersifat hubungan kausal yang menggambarkan hubungan sebab variabel dependen dan independen terkait sebab akibat (Sugiyono, 2014).

Populasi dan Sampel

Mengacu (Sugiyono, 2014) Populasi adalah objek dan subjek yang memiliki kualitas untuk kemudian disimpulkan. Pada penelitian ini dimanfaatkan populasi yakni Perusahaan Aneka Industri di Bursa Efek Indonesia periode 2016-2019. Mengacu (Sugiyono, 2014) Sampel diartikan sebagai 
bagian populasi dengan kriteria dan jumlah tertentu. Teknik pengambilan sampel yang dimanfaatkan yakni purposive sampling. Mengacu (Sugiyono, 2014) Purposive sampling diartikan sebagai teknik untuk mengambil sampel dari populasi disesuaikan dengan karakteristiknya dan sudah dicocokkan. Adapun kriterianya sebagai berikut:

Tabel 1. Kriteria Penarikan Sampel

\begin{tabular}{|l|l|c|}
\hline No & \multicolumn{1}{|c|}{ Kriteria } & $\begin{array}{c}\text { Total } \\
\text { Perusahaan }\end{array}$ \\
\hline 1 & Perusahaan Sektor Aneka Industri yang terdaftar di Bursa Efek Indonesia & 45 \\
\hline 2 & $\begin{array}{l}\text { Perusahaan Sektor Aneka Industri yang tidak mempublikasikan laporan } \\
\text { keuangan secara lengkap pada periode 2016-2019 }\end{array}$ & $(21)$ \\
\hline 3 & $\begin{array}{l}\text { Perusahaan Sektor Aneka Industri yang memiliki laba negatif periode } \\
2016-2018\end{array}$ & $(11)$ \\
\hline \multicolumn{2}{|l|}{ Total perusahaan yang dijadikan sampel 13 perusahaan x 4 tahun } & 52 \\
\hline
\end{tabular}

Peneliti menggunakan teori penunjang dan data mengacu pada buku penunjang ataupun berbentuk jurnal sehingga permasalahan penelitian dapat terkumpul dan terjawab. Penelitian menggunakan data sekunder. Mengacu (Sugiyono, 2014) data sekunder disediakan dan pengumpulannya dilaksanakan orang lain.

\section{Uji Normalitas}

\section{HASIL}

Tabel 2. One-Sample Kolmogorov-Smirnov Test

\begin{tabular}{|l|l|r|}
\hline \multicolumn{2}{|l|}{} & Unstandardized Residual \\
\hline $\mathrm{N}$ & Mean & 35 \\
\cline { 2 - 3 } Normal Parameters & Std. Deviation & .0002644 \\
\hline \multirow{3}{*}{ Most Extreme Differences } & Absolute & .00413391 \\
\cline { 2 - 3 } & Positive & .133 \\
\cline { 2 - 3 } & Negative & .133 \\
\hline Kolmogorov-Smirnov Z & -.075 \\
\hline Asymp. Sig. (2-tailed) & .788 \\
\hline
\end{tabular}

Sumber : Data diolah Output SPSS 20

Mengacu pengujian Kolmogorov-Smirnov mampu diketahui asymp.Sig. (2-tailed) nilainya $\geq$ 0.05 , kesimpulannya data mempunyai distribusi normal.

\section{Uji Multikolinearitas}

Tabel 3. Uji Multikolinearitas

\begin{tabular}{|l|l|r|r|}
\hline \multicolumn{2}{|l|}{ Model } & \multicolumn{2}{|c|}{ Collinearity Statistics } \\
\hline \multicolumn{1}{|l||}{} & Tolerance & VIF \\
\hline \multirow{4}{*}{1} & & \\
\cline { 2 - 4 } & CR & .542 & 1.847 \\
\cline { 2 - 4 } & DER & .628 & 1.591 \\
\cline { 2 - 4 } & TATO & .876 & 1.142 \\
\cline { 2 - 4 } & NPM & .778 & 1.285 \\
\hline
\end{tabular}

Sumber : Data diolah Output SPSS 20

Uji multikolinieritas menjadi pengujian guna pengujian antar variabel independen apakah terdapat korelasi ataukah tidak. Dalam hal ini mampu diuji melalui nilai Tolerance $\geq 0.1$ serta nilai VIF $\leq 10$ yang pada permodelan regresi artinya multikolinieritas tidak terjadi (Imam 2013).Mengacu pengujian multikolinearitas diketahui VIF $<10$ dengan nilai tolerance $\geq 0.1$, kesimpulannya yakni gejala multikolinearitas tidak terjadi.

\section{Uji Heteroskedastisitas}




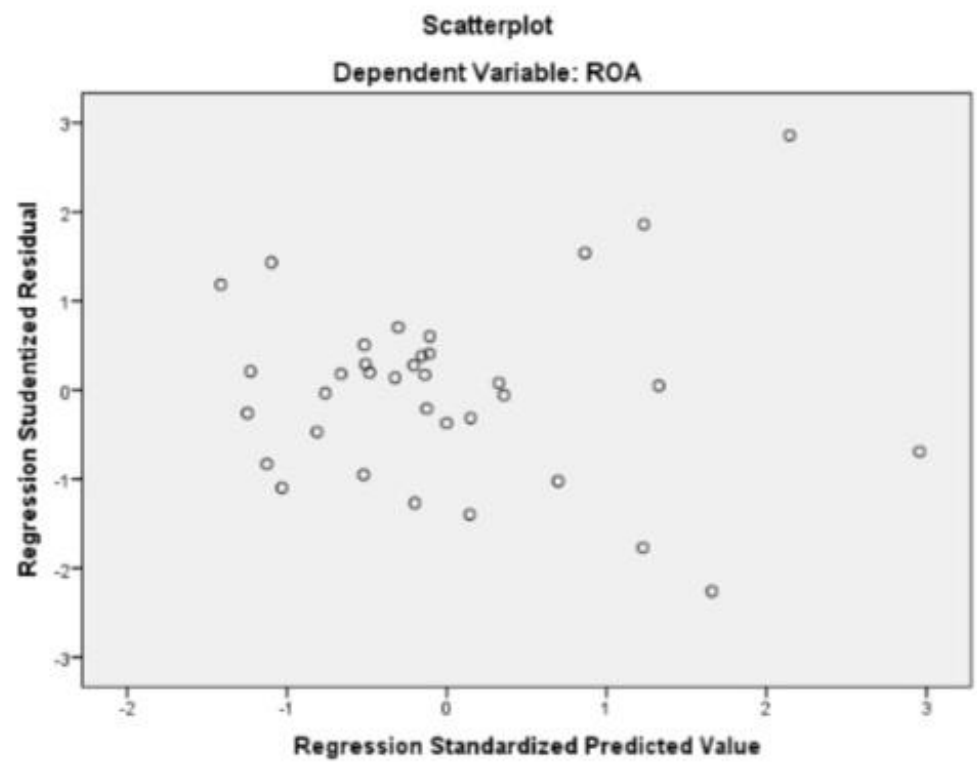

Gambar 2. Scatterplots

Sumber : Data diolah Output SPSS 20

Uji heteroskedastisitas memiliki tujuan guna melakukan pengujian model regresi secara residual apakah terjadi perbedaan dari suatu pengamatan dengan pengamatan lainnya. Pada pengujian heteroskedastisitas dalam pengujian scatterplots dapat diketahui titik tersebar sumbu Y diatas maupun dibawah angka 0 dengan baik dan terkumpulnya bukan di satu tempat, maka dari itu bisa dikatakan gejala heteroskedastisitas tidak terjadi_(Ghozali, 2013).

Dalam uji glejser dilihat variabel Current Ratio (X1) bernilai signifikasinya 0.93 ,variabel Debt To Equity Ratio (X2) bernilai signifikasi 0.380, variabel Total Assets Turn Over (X3) bernilai signifikasi 0.193 serta nilai signifikan variabel Net Profit Margin (X4) adalah 0.90. Nilai signifikan $\mathrm{X} 1, \mathrm{X} 2, \mathrm{X} 3$ dan $\mathrm{X} 4 \geq 0.05$. Maka dari itu terbukti gejala heteroskedastisitas tidak terjadi.

Tabel 4. Uji Glejser

\begin{tabular}{|c|c|c|c|c|c|c|}
\hline \multirow{2}{*}{\multicolumn{2}{|c|}{ Model }} & \multicolumn{2}{|c|}{ Unstandardized Coefficients } & \multirow{2}{*}{\begin{tabular}{|c} 
Standardized Coefficients \\
Beta \\
\end{tabular}} & \multirow[t]{2}{*}{$\mathrm{t}$} & \multirow[t]{2}{*}{ Sig. } \\
\hline & & $\mathrm{B}$ & Std. Error & & & \\
\hline \multirow{5}{*}{1} & (Constant) & -.004 & .003 & & -1.357 & .185 \\
\hline & $\mathrm{CR}$ & .001 & .001 & .376 & 1.735 & .093 \\
\hline & DER & .001 & .001 & .179 & .890 & .380 \\
\hline & TATO & .003 & .002 & .227 & 1.332 & .193 \\
\hline & NPM & .035 & .020 & .316 & 1.750 & .090 \\
\hline
\end{tabular}

Sumber : Data diolah SPSS 20

\section{Uji Autokorelasi}

Tabel 5. Durbin-Watson

\begin{tabular}{|l|r|r|r|r|r|}
\hline Model & \multicolumn{1}{|c|}{$\mathrm{R}$} & R Square & $\begin{array}{c}\text { Adjusted R } \\
\text { Square }\end{array}$ & $\begin{array}{c}\text { Std. Error of the } \\
\text { Estimate }\end{array}$ & Durbin-Watson \\
\hline 1 & $.989^{\mathrm{a}}$ & .977 & .974 & .004294407 & 1.767 \\
\hline
\end{tabular}

Sumber : Data diolah SPSS 20

Uji autokorelasi memiliki tujuan guna melakukan pengujian model regresi linear terkait hubungan residual periode $t$ dan residual periode $t-1$ (tahun lalu)_(Ghozali, 2013). Pada autokorelasi mampu diketahui nilai Durbin-Watson yakni 1.767 dimana artinya nilai tersebut ada diantara -2 dan 2 dan bebas gejala autokorelasi. 
Owner: Riset \& Jurnal Akuntansi

e-ISSN : 2548-9224 |p-ISSN : 2548-7507

Volume 2 Nomor 2, Agustus 2021

DOI : https://doi.org/10.33395/owner.v5i2.430

\section{Persamaan Regresi Linear Berganda}

Tabel 6. Persamaan Regresi Berganda

\begin{tabular}{|c|c|c|c|c|c|c|c|c|}
\hline \multirow{2}{*}{\multicolumn{2}{|c|}{ Model }} & \multicolumn{2}{|c|}{$\begin{array}{l}\text { Unstandardized } \\
\text { Coefficients }\end{array}$} & \multirow{2}{*}{$\begin{array}{l}\text { Standardized } \\
\text { Coefficients } \\
\text { Beta }\end{array}$} & \multirow[t]{2}{*}{$\mathrm{t}$} & \multirow[t]{2}{*}{ Sig. } & \multicolumn{2}{|c|}{$\begin{array}{c}\text { Collinearity } \\
\text { Statistics }\end{array}$} \\
\hline & & B & Std. Error & & & & Tolerance & VIF \\
\hline \multirow{5}{*}{1} & (Constant) & -.038 & .005 & & -7.275 & .000 & & \\
\hline & CR & -.001 & .001 & -.047 & -1.248 & .222 & .542 & 1.847 \\
\hline & DER & -.001 & .001 & -.033 & -.961 & .344 & .628 & 1.591 \\
\hline & TATO & .036 & .003 & .322 & 10.922 & .000 & .876 & 1.142 \\
\hline & NPM & 1.113 & .033 & 1.058 & 33.816 & .000 & .778 & 1.285 \\
\hline
\end{tabular}

Sumber : Data diolah SPSS 20

Penafsiran pada persamaan regresi berganda adalah:

1. Konstanta

Konstanta dengan nilai -0.038. Ini memiliki makna bila nilai variabel CR, DER, TATO dan NPM dianggap tetap, Return On Assets akan bergerak sebesar-0.038.

2. Current Ratio

Variabel CR bernilai negatif yaitu -0.001. Ini memiliki makna setiap penurunan 1 satuan Current Ratio, maka Return On Assets akan naik karena tanda negatif menunjukkan hubungan yang berlawanan arah.

3. Debt To Equity Ratio

Variabel DER bernilai negatif yaitu -0.001. Ini memiliki makna turunnya 1 satuan DER, ROA akan naik karena tanda negatif menunjukkan hubungan yang berlawanan arah.

4. Total Assets Turn Over

Variabel TATO positif yaitu 0.036. Ini memiliki makna naiknya 1 satuan Total Assets Turn Over, Return On Assets naik sebesar 0.036 satuan.

5. Net Profit Margin

Variabel NPM bernilai positif yaitu 1.113. Ini memiliki makna naiknya 1 satuan Net Profit Margin, Return On Assets akan naik sebesar 1.113 satuan.

\section{Koefisien Determinasi}

Tabel 7. Koefisien Determinasi

\begin{tabular}{|l|r|r|r|r|r|}
\hline Model & \multicolumn{1}{|c|}{$\mathrm{R}$} & R Square & $\begin{array}{c}\text { Adjusted R } \\
\text { Square }\end{array}$ & $\begin{array}{c}\text { Std. Error of the } \\
\text { Estimate }\end{array}$ & Durbin-Watson \\
\hline 1 & $.989^{\mathrm{a}}$ & .977 & .974 & .004294407 & 1.767 \\
\hline
\end{tabular}

Sumber : Data diolah Output SPSS 20

Koefisien determinasi (R2) bertujuan guna pengukuran seberapa jauhnya model dapat memberikan penjelasan variabel dependen dan variasinya. Koefisien determinasi mempunyai nilai yakni pada rentang $0<X<1$ _(Ghozali, 2013).

Uji Koefisien Determinasi didapatkan Adjusted R2 bernilai 0.974 artinya $97.4 \%$ variabel independen berpengaruh pada kinerja keuangan sebesar $97.4 \%$ sementara sisanya $2.6 \%$ terpengaruh variabel lain.

\section{Uji F}

Tabel 8. Uji F

\begin{tabular}{|l|l|r|r|r|c|c|}
\hline \multicolumn{2}{|l|}{ Model } & Sum of Squares & df & Mean Square & F & Sig. \\
\hline \multirow{3}{*}{1} & Regression & .024 & 4 & .006 & 320.828 & $.000^{\mathrm{b}}$ \\
\cline { 2 - 7 } & Residual & .001 & 30 & .000 & & \\
\cline { 2 - 7 } & Total & .024 & 34 & & & \\
\hline
\end{tabular}

Sumber : Data diolah Output SPSS 20

Uji statistik F memiliki tujuan guna menggambarkan seluruh variabel independent (bebas) apakah terdapat pengaruh bagi variabel dependen (terikat) bersamaan_(Ghozali, 2013). 
Mengacu Uji F dapat diketahui nilai Fhitung sebesar 320.828 dan nilai signifikannya 0.000, sementara nilai Ftabel yakni dan nilai signifikannya 0.05. Dengan demikian Fhitung > Ftabel $(320.828$ > 2.69) memenuhi syarat secara bersamaan CR ,DER, TATO dan NPM ada pengaruh bagi ROA.

\section{Uji T}

Tabel 9. Uji T
\begin{tabular}{|c|l|r|r|}
\multicolumn{2}{|l}{ Model } & \multicolumn{1}{c|}{$\mathrm{t}$} & Sig. \\
\hline \multirow{4}{*}{1} & (Constant) & -7.275 & .000 \\
\cline { 2 - 4 } & CR & -1.248 & .222 \\
\cline { 2 - 4 } & DER & -.961 & .344 \\
\cline { 2 - 4 } & TATO & 10.922 & .000 \\
\cline { 2 - 4 } & NPM & 33.816 & .000 \\
\hline
\end{tabular}

Sumber : Data diolah Output SPSS 20

Mengacu Uji T diketahui yakni :

a. Current Ratio (X1) didapatkan nilai thitung yakni -1.248 dimana nilai signifikannya 0.222. Maka dari itu, nilai -thitung >-ttabel atau -1.248> -2.042 maka H0 diterima Ha ditolak, yang berarti Current ratio tidak mempengaruhi kinerja keuangan dalam perusahaan sektor aneka industri 2016-2019.

b. Debt To Equity Ratio (X2) didapatkan nilai thitung yakni -0.961 dimana nilai signifikannya 0.344. Maka dari itu, nilai -thitung>-ttabel atau -0.961>-2.042 maka H0 diterima Ha ditolak, yang berarti Debt To Equity Ratio tidak mempengaruhi kinerja keuangan dalam perusahaan sektor aneka industri 2016-2019.

c. Total Assets Turn Over didapatkan nilai thitung yakni 10.922 dimana nilai signifikannya 0.000. Maka dari itu, nilai thitung >ttabel atau 10.922>2.042 maka H0 ditolak Ha diterima, yang berarti Total Assets Turn Over mempengaruhi kinerja keuangan dalam perusahaan sektor aneka industri 2016-2019.

d. Net Profit Margin didapatkan nilai thitung yakni 33.816 dimana nilai signifikannya 0.000. Maka dari itu, nilai thitung>ttabel atau 33.816>2.042 maka H0 ditolak Ha diterima, yang berarti Net Profit Margin mempengaruhi kinerja keuangan dalam perusahaan aneka industri 2016-2019.

\section{PEMBAHASAN}

Berdasarkan uji hipotesis (Uji t) dapat dilihat tidak ada pengaruh Current Ratio terhadap ROA Nilai CR terlalu tinggi juga bisa diartikan sebagai aktiva perusahaan yang tidak digunakan dengan maksimal. Hasil penelitian ini sesuai penelitian_(Wijayanti, Citra , \& Achyani, 2019) dan _(Eka \& Cunengsih, 2018) dikarenakan perusahaan diharapkan mengolah modal kerja yang menganggur dengan baik. DER tidak ada pengaruh terhadap ROA. Hasil penelitian ini sejalan dengan penelitian (Laela \& Hendratno, 2019) dan_(Wijayanti, Citra , \& Achyani, 2019 )_dikarenakan rendahnya beban hutang dapat meningkatkan laba yang diterima perusahaan. Selanjutnya, TATO terdapat pengaruh terhadap Kinerja Keuangan. Hasil penelitian ini sesuai kajian_(Eka \& Cunengsih, 2018) dan (Alpi, 2018) dikarenakan meningkatnya penjualan berpengaruh terhadap laba yang dihasilkan. Sedangkan NPM terdapat pengaruh terhadap Kinerja Keuangan. Hasil penelitian ini sesuai penelitian _(Wahyudi \& Sitohang, 2017) dan _(Winarno, 2019) dikarenakan peningkatan atau penurunan NPM mempunyai peran agar dapat mengetahui kinerja keuangan.

\section{KESIMPULAN}

Nilai CR, DER, TATO dan NPM memiliki pengaruh signifikan terhadap Kinerja Keuangan secara simultan. Secara parsial CR dan DER tidak ada pengaruh terhadap Kinerja Keuangan sedangkan TATO dan NPM memilki pengaruh terhadap Kinerja Keuangan pada Perusahaan Sektor Aneka Industri 2016-2019 dengan ROA sebagai variabel moderating. 


\section{REFERENSI}

Alpi, M. F. (2018). Pengaruh Debt to Equity Ratio, Inventory Turn Over, dan Current Ratio terhadap Return on Equity pada Perusahaan Sektor Farmasi yang Terdaftar di Bursa Efek Indonesia. The National Conference on Management and Business (NCMAB) 2018 (pp. 158-175). Surakarta: Universitas Muhammadiyah Surakarta.

Angelina, C., Sharon, S., Lim, S., Lombogia, J. Y., \& Aruan, D. A. (2020). Pengaruh Current Ratio, Debt to Equity, Perputaran Kas dan Total Asset TurnOver (TATO) Terhadap Profitabilitas pada Perusahaan Food \& Beverages yang terdaftar di Bursa Efek Indonesia. Owner: Riset dan jurnal Akuntansi, 16-27.

Anggraeni, A., \& Elisa, A. M. (2020). PENGARUH CURRENT RATIO, DEBT TO EQUITY RATIO, TOTAL ASSETS TURNOVER DAN NET PROFIT MARGIN SEBAGAI ALAT UKUR UNTUK MENILAI KINERJA KEUANGAN STUDI KASUS PADA PERUSAHAAN YANG BERGERAK DI BIDANG MANUFAKTUR YANG TERDAFTAR DI BEI. Surabaya: Univesitas Bhayangkara Surabaya.

Eka, S. D., \& Cunengsih, C. (2018). Pengaruh debt to equity ratio dan current ratio terhadap return on assets Pada PT. Midi Utama Indonesia, Tbk. ACCOUNT: Jurnal Akuntansi Keuangan dan Perbankan, -.

Fahmi, I. (2012). Analisis Kinerja Keuangan. Bandung: CV. Alfabeta.

Ghozali, I. (2013). Aplikasi Analisis Multivariate Dengan Program IBM SPSS 21 Update PLS Regresi. Semarang: Univesitas Diponegoro.

Harsi, R., Munandar, A., Yamin, A., \& Sus, Y. (2017). Faktor-faktor yang Mempengaruhi Return on Asset Perusahaan Sektor Perkebunan yang terdaftar di Bursa Efek Indonesia Tahun 2011-2016. Jurnal Manajemen dan Bisnis Sriwijaya (JMBS), 208-215.

Jayanti, F. D., \& Lestari, U. P. (2018). PENGARUH DEBT TO EQUITY RATIO (DER) CURRENT RATIO(CR), GROOS PROFIT MARGIN (GPM), NET PROFT MARGIN (NPM), UKURAN PERUSAHAAN, WORKING CAPITAL TO TOTAL ASSET (WCTA) TERHADAP PERTUMBUHAN LABA. Prima Ekonomi: Jurnal Ekonomi dan Bisnis, 21-32.

Kasmir, K. (2018). Analisis Laporan Keuangan. Jakarta: PT. Raja Grafindo.

Laela, R. H., \& Hendratno, H. (2019). APENGARUH CURRENT RATIO, DEBT TO EQUITY RATIO DAN TOTAL ASSET TURNOVER TERHADAP RETURN ON ASSET. JASa (Jurnal Akuntansi Audit dan Sistem Informasi Akuntansi), 120-131.

Rahmi, A., Indrawan, A., \& Sudarma, A. (2020). Pengaruh Total Debt Equity Ratio (DER) dan Total Asset Turnover (TATO) Terhadap Profitabilitas (ROE) pada Perusahaan Manufaktur yang Terdaftar di Bursa Efek. BUDGETING : Journal of Business, Management and Accounting, 73-82.

Rhamadana, R. B., \& Triyonowati, T. (2016). ANALISIS RASIO KEUANGAN UNTUK MENILAIN KINERJA KEUANGAN PADA PT. H.M SAMPOERNA Tbk. Jurnal Ilmu dan Riset Manajemen (JIRM), -.

Setiyono, E., \& Amanah, L. (2016). PENGARUH KINERJA KEUANGAN DAN UKURAN PERUSAHAAN TERHADAP RETURN SAHAM. Jurnal Ilmu dan Riset Akuntansi (JIRA), -.

Sugiyono, S. (2014). Penelitian Pendidikan Pendekatan Kuantitatif, Kualitatif Dan R\&D. Bandung: CV. Alfabeta.

Wahyudi, Y., \& Sitohang, S. (2017). PENGARUH NPM, CR, DER, TATO TERHADAP KINERJA KEUANGAN PT. PERKEBUNAN NUSANTARA X. Jurnal Ilmu dan Riset Manajemen (JIRM), 1-15.

Widodo, A. (2018). ANALISIS PENGARUH CURRENT RATIO (CR), TOTAL ASSET TURNOVER (TATO), DAN DEBT TO ASSET RATIO (DAR) TERHADAP RETURN ON ASSET (ROA), SERTA DAMPAKNYA TERHADAP NILAI PERUSAHAAN. Jurnal Ilmiah Manajemen FORKAMMA, 87-112.

Wijayanti, W., Citra , M. P., \& Achyani, F. (2019 ). Analisis Rasio Keuangan Dan Struktur Kepemilikan Terhadap Kinerja Keuangan (Studi Empiris Pada Perusahaan Manufaktur 
Owner: Riset \& Jurnal Akuntansi

e-ISSN : 2548-9224 |p-ISSN : 2548-7507

Volume 2 Nomor 2, Agustus 2021

Yang Terdaftar Di Bursa Efek Indonesia Periode 2014-2017). Surakarta: Universitas Muhammadiyah Surakarta.

Winarno, S. H. (2019). Analisis NPM, ROA, dan ROE dalam Mengukur Kinerja Keuangan. Jurnal STEI Ekonomi, 254-266. 